\title{
Tacrolimus Protects against Age-Associated Microstructural Changes in the Beagle Brain
}

\author{
Hamsanandini Radhakrishnan, ${ }^{1}$ Margo F. Ubele, ${ }^{2}$ Stephanie M. Krumholz, ${ }^{2}$ Kathy Boaz, ${ }^{2}$ Jennifer L. Mefford, ${ }^{3}$ \\ Erin Denhart Jones, ${ }^{3}$ Beverly Meacham, ${ }^{4}$ Jeffrey Smiley, ${ }^{3}$ László G. Puskás, ${ }^{5}$ David K. Powell, ${ }^{4}$ \\ Christopher M. Norris, ${ }^{2}$ Craig E. L. Stark, ${ }^{1,6}$ and Elizabeth Head ${ }^{7}$ \\ ${ }^{1}$ Mathematical, Computational and Systems Biology, University of California, Irvine, Irvine, California 92697, ${ }^{2}$ Sanders Brown Center on Aging, \\ Department of Pharmacology and Nutritional Sciences, College of Medicine, University of Kentucky, Lexington, Kentucky 40506, ${ }^{3}$ Division of \\ Laboratory Animal Resources, University of Kentucky, Lexington, Kentucky 40506, ${ }^{4}$ Magnetic Resonance Imaging and Spectroscopy Center, \\ University of Kentucky, Lexington, Kentucky 40506, ${ }^{5}$ Aperus Pharma, H-6726, Szeged, Hungary, ${ }^{6}$ Department of Neurobiology and Behavior, \\ University of California, Irvine, Irvine, California 92697, and ${ }^{7}$ Department of Pathology \& Laboratory Medicine, University of California, Irvine, \\ Irvine, California 92697
}

The overexpression of calcineurin leads to astrocyte hyperactivation, neuronal death, and inflammation, which are characteristics often associated with pathologic aging and Alzheimer's disease. In this study, we tested the hypothesis that tacrolimus, a calcineurin inhibitor, prevents age-associated microstructural atrophy, which we measured using higher-order diffusion MRI, in the middle-aged beagle brain $(n=30$, male and female). We find that tacrolimus reduces hippocampal $(p=0.001)$ and parahippocampal $(p=0.002)$ neurite density index, as well as protects against an age-associated increase in the parahippocampal $(p=0.007)$ orientation dispersion index. Tacrolimus also protects against an age-related decrease in fractional anisotropy in the prefrontal cortex $(p<0.0001)$. We also show that these microstructural alterations precede cognitive decline and gross atrophy. These results support the idea that calcineurin inhibitors may have the potential to prevent aging-related pathology if administered at middle age.

Key words: aging; Alzheimer's disease; calcineurin; canine; diffusion-weighted imaging; neuroinflammation

Significance Statement

Hyperactive calcineurin signaling causes neuroinflammation and other neurobiological changes often associated with pathologic aging and Alzheimer's disease (AD). Controlling the expression of calcineurin before gross cognitive deficits are observable might serve as a promising avenue for preventing $\mathrm{AD}$ pathology. In this study, we show that the administration of the calcineurin inhibitor, tacrolimus, over 1 year prevents age- and AD-associated microstructural changes in the hippocampus, parahippocampal cortex, and prefrontal cortex of the middle-aged beagle brain, with no noticeable adverse effects. Tacrolimus is already approved by the Food and Drug Administration for use in humans to prevent solid organ transplant rejection, and our results bolster the promise of this drug to prevent $\mathrm{AD}$ and aging-related pathology.

\section{Introduction}

Alzheimer's disease $(\mathrm{AD})$ is the most prevalent neurodegenerative disorder in the world, affecting $>45$ million people (Dos Santos Picanco et al., 2018). It is primarily characterized by

Received Feb. 12, 2021; revised Apr. 9, 2021; accepted Apr. 16, 2021.

Author contributions: D.K.P., C.M.N., and E.H. designed research; M.F.U., S.M.K., K.B., J.L.M., E.D.J., B.M., and J.S. performed research; L.G.P. contributed unpublished reagents/analytic tools; H.R. and C.E.L.S. analyzed data; H.R., C.E.L.S., and E.H. wrote the paper.

This study was funded by National Institutes of Health Grant R01-AG-056998, given to E.H. and C.M.N. We thank Aperus Pharma for supporting one arm of the baseline data of the study. We also thank Frederick Bresch at the University of Kentucky for support with the cognitive testing software.

The authors declare they have no conflict of interest.

Correspondence should be addressed to Elizabeth Head at heade@uci.edu.

https://doi.org/10.1523/JNEUROSCI.0361-21.2021

Copyright $\odot 2021$ the authors dementia, a decline in memory, and other cognitive skills beyond what is typically observed in healthy aging (Reitz and Mayeux, 2014). The greatest risk factor for AD remains age, and most people in whom the disease develops are older than 65 years (Inouye et al., 2010).

The two major neuropathological features of $\mathrm{AD}$ are abnormally folded $\beta$-amyloid (A $\beta$ ) peptides and the accumulation of hyperphosphorylated tau proteins in amyloid plaques and neurofibrillary tangles (Perl, 2010; Holtzman et al., 2011; Stancu et al., 2014; Forestier et al., 2015; Hendrie et al., 2015; Liu et al., 2015). Because of the overwhelming evidence that $\mathrm{A} \beta$ plaques play a role in $\mathrm{AD}$ and the amyloid cascade hypothesis (Hardy and Higgins, 1992), most therapeutic strategies have focused on reducing or at least controlling the formation of these plaques. However, clinical trials that use $\mathrm{A} \beta$-reducing approaches have 
shown limited clinical efficacy, prompting the exploration of treatments that target other factors or pathways driving this disease, perhaps upstream of $\mathrm{A} \beta$ accumulation (Pahnke et al., 2009).

Mounting evidence suggests that the $\mathrm{Ca}^{2+} /$ calmodulin-dependent protein phosphatase, calcineurin, and downstream signaling pathways are an attractive target for ameliorating cognitive decline in $\mathrm{AD}$ and related disorders (Reese and Taglialatela, 2011; Sompol and Norris, 2018). Calcineurin is found at high levels in neurons and reactive glial cells where it modulates synaptic plasticity, neuroinflammation, glutamate regulation, and memory formation (Mansuy, 2003). Elevated levels of calcineurin expression and signaling are found in the hippocampus and other cortical areas at the outset of cognitive decline in humans (Abdul et al., 2009; Mohmmad Abdul et al., 2011) and are highly correlated with pathologic features in later disease stages (Liu et al., 2005; Abdul et al., 2009). Overexpression or hyperactivation of calcineurin in experimental models recapitulates key features of $\mathrm{AD}$, including glial reactivity (Norris et al., 2005), synaptic degeneration (Wu et al., 2010), and cognitive dysfunction (Malleret et al., 2001). Conversely, the inhibition of calcineurin signaling via genetic or pharmacologic means reverses many of these $\mathrm{AD}$ related biomarkers in animal models (Reese et al., 2008; Taglialatela et al., 2009; Rozkalne et al., 2011; Furman et al., 2012; Hudry et al., 2012; Rojanathammanee et al., 2015; Kumar and Singh, 2017; Sompol et al., 2017). In the clinic, calcineurin inhibitors, like tacrolimus, are used primarily as immunosuppressants to combat organ transplant rejection and other autoimmune disorders. However, an epidemiological study in 2015 showed that kidney transplant patients treated with tacrolimus had a significantly lower incidence of dementia relative to age-matched individuals in the general population (Taglialatela et al., 2015). Collectively, this work suggests that tacrolimus and other Food and Drug Administration (FDA)-approved calcineurin inhibitors could be repurposed for the prevention of $\mathrm{AD}$ and dementia.

The FDA-approved status, and the well known safety profiles and contraindications of calcineurin inhibitors would certainly make the path to AD clinical trials easier. But, to ensure that calcineurin inhibitors have the best chance of succeeding as anti$\mathrm{AD}$ therapeutics requires further optimization in a preclinical model that better approximates human metabolism, neural function, treatment course, and biomarker milestones.

Dogs have a metabolism that is very similar to that of humans and are excellent preclinical models for testing pharmacological agents (Dalgaard, 2015). More importantly for investigating antiAD treatments, dogs naturally show age-related amyloid plaque pathology, neuroinflammation, and neurodegeneration (Sarasa and Pesini, 2009; Prpar Mihevc and Majdič, 2019). Human-like deficits in cognition also arise with aging and correlate well with pathologic features. Because of their longer life span, larger brain size, and complexity, and ease of training, dogs are amenable to the longitudinal assessment of neurologic function using complex cognitive/behavioral batteries and brain imaging, which are common to most modern human clinical trials. (Patronek et al., 1997; Hoffman et al., 2018). Given these clear benefits, we explored the microstructural consequences of tacrolimus on the brain of a preclinical aging beagle model (age, 4-8 years) using diffusion-weighted imaging (DWI). Though traditional MRI procedures (like T1- and T2-weighted imaging) are noninvasive, they only provide a mesoscopic view as even their highest resolutions are well too coarse to resolve changes at the expected microscopic level, at least directly. In contrast, DWI provides measures that are sensitive to the underlying microstructure and its changes in disorders such as AD (Chua et al., 2008). Here, we use the following two types of diffusion analysis techniques to survey the potential cytoarchitectural changes (or lack thereof) that tacrolimus could induce in the beagle brain: (1) traditional diffusion tensor fitting (Basser et al., 1994); and (2) neurite orientation dispersion and density imaging (NODDI) analysis (Zhang et al., 2012).

\section{Materials and Methods}

Animals and drug delivery

Forty-five ( 7 males and 38 females) purpose-bred beagles ranging in age from 5 to 8 years were assessed for general health status and cognition, as described previously (Head et al., 1998; Milgram et al., 1999, 2002; Tapp et al., 2003; Christie et al., 2005; Studzinski et al., 2006). Dogs ranged in weight from 8.6 to $14.5 \mathrm{~kg}$. Since tacrolimus has previously been associated with nephrotoxicity in renal transplant patients (Randhawa et al., 1997), blood samples were taken every 6 months to monitor the overall health and to assess blood urea nitrogen (BUN), creatine, and phosphorous levels of the dogs. All institutional and national guidelines for the care and use of laboratory animals were followed.

\section{Cognitive testing}

Cognitive testing used a modified Wisconsin General Test Apparatus described previously (Head et al., 2008). Dogs were given 10-12 trials/d, $5 \mathrm{~d} /$ week, depending on the cognitive task. All tasks were reward motivated and based on visual cues. Dogs were given baseline tests of visual discrimination learning and reversal learning to assess learning and executive function. Subsequently, a spatial delayed nonmatch to sample task was used to assess spatial learning and memory. At the end of baseline testing, dogs were ranked according to cognitive test scores and balanced into three groups consisting of 15 animals/group. Groups were also balanced for age.

\section{Drug administration}

Oral tacrolimus at a concentration of $0.075 \mathrm{mg} / \mathrm{kg}$ twice a day $(n=15$; two males) or an oral placebo control ( $n=15$; two males) was administered for 1 year. The remaining 15 animals were assigned to another intervention study not relevant to this article; only their baseline data are included here to improve the statistical power of age associations. The concentration of the drugs was designed to provide minimal immunosuppression to reduce adverse effects (Margarit et al., 1998).

\section{MRI image acquisition}

Dogs were placed under general anesthesia using propofol $(4-8 \mathrm{mg} / \mathrm{kg}$, i. v., by slow injection to effect). After orotracheal intubation and maintenance on isoflurane $1-4 \%$, delivered in $100 \% \mathrm{O}_{2}$, dogs were scanned using a 3 T MRI scanner (Prisma, Siemens) both at baseline before treatment and after 1 year of treatment.

T1 weighted. A high-resolution T1-weighted (T1w) MPRAGE image was collected [repetition time $(\mathrm{TR})=2530 \mathrm{~ms}$; echo time $(\mathrm{TE})=2.49 \mathrm{~ms}$; flip angle $=7^{\circ}$; matrix size $=0.4 \times 0.4 \times 0.7 \mathrm{~mm}$; averages $=1$; average acquisition time $=10 \mathrm{~min}, 30 \mathrm{~s}$ ] for structural analysis and image registration.

DWI. Diffusion imaging $(\mathrm{TR}=5700 \mathrm{~ms}$; $\mathrm{TE}=62 \mathrm{~ms} ; 48$ coronal slices in the animal reference frame; phase encoding, superior-inferior; average acquisition time $=12 \mathrm{~min}, 30 \mathrm{~s}$ ) was performed using a double refocused echoplanar sequence with an isotropic $1.6 \mathrm{~mm}$ voxel for three gradient values: $b=500,1000$, and $2000 \mathrm{~s} / \mathrm{mm}^{2}$. Gradients were applied in a total of 114 directions, along with 13 images with no diffusion weighting $(b=0)$.

\section{Diffusion data preprocessing}

All preprocessing steps used MRtrix3 (Tournier et al., 2012; https:// www.mrtrix.org/) commands or MRtrix3 scripts that linked external software packages. Physiologic noise arising from thermal motion of water molecules in the brain was removed first (Veraart et al., 2016), followed by the removal of Gibbs ringing artifacts (Kellner et al., 2016). The image intensity was then normalized across subjects in the log-domain (Raffelt et al., 2012; Andersson and Sotiropoulos, 2016). 


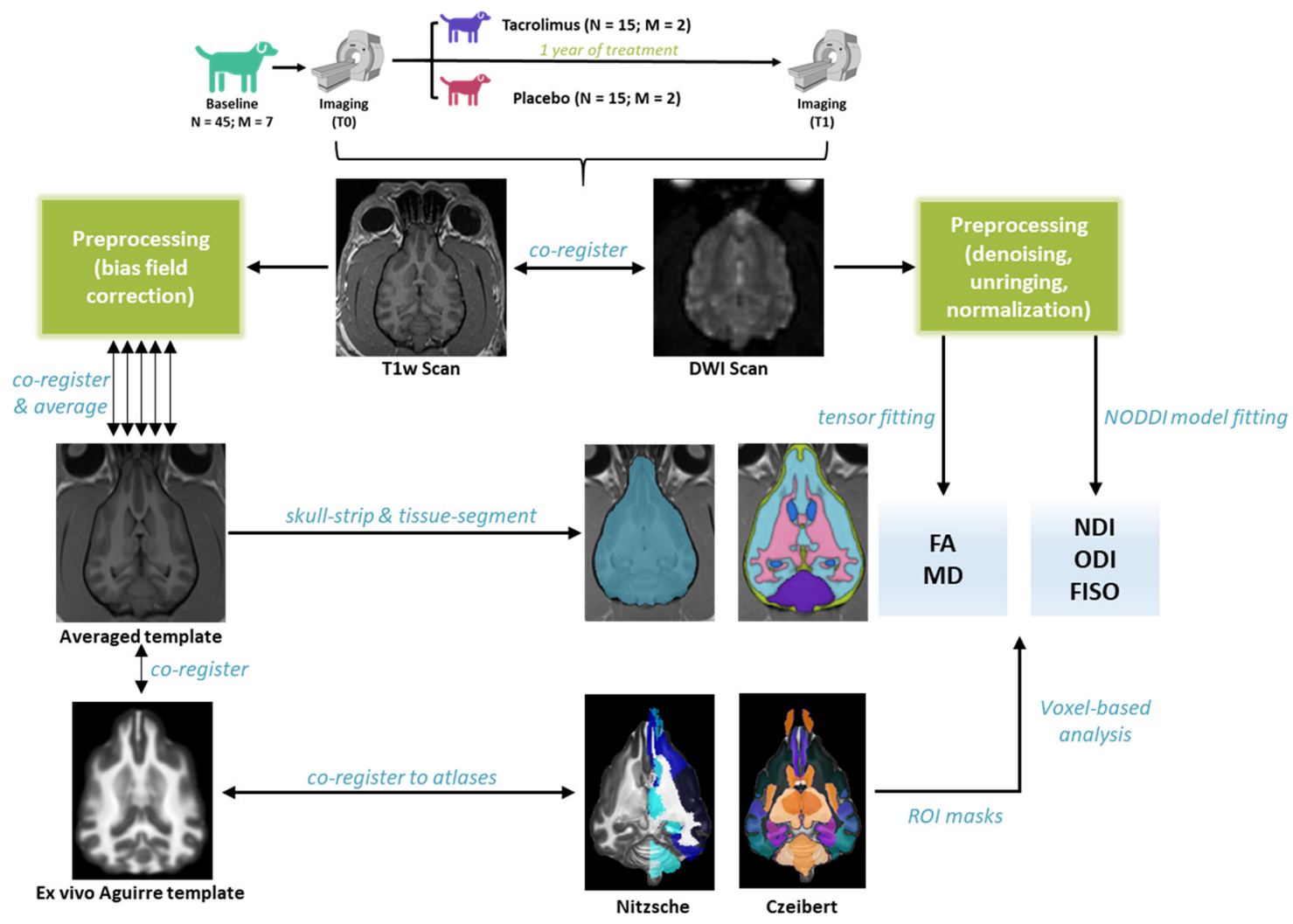

Figure 1. Summary of the analysis pipeline.

\section{Structural data processing}

The T1w images were corrected for intensity inhomogeneities using advanced normalizations tools (ANTs) N4 bias field correction (Tustison et al., 2010). The structural image of each dog was then nonlinearly coregistered to their respective preprocessed b0 image, so that the structural and diffusion images were in the same space for the rest of the analyses. To help standardize our results, we used the Aguirre high-resolution ex vivo template (Datta et al., 2012). In this space, we generated a high-resolution central tendency template from the structural scans using ANTs with an initial cohort of 10 animals and a bootstrapping approach. We then used this template to generate initial priors for both brain extraction and tissue type segmentation (gray matter, white matter, CSF, deep gray matter, and cerebellum) again using ANTs and a bootstrapping approach with more refined priors. The result was a set of priors that can be used in a modified ANTs cortical thickness pipeline to generate final tissue segments for each subject. Though the Aguirre template provides an excellent standard template space complete with high-resolution ex vivo scans, it does not provide adequate labels for ROI-specific analyses. To solve this problem, we coregistered two different atlases, hereby referred to as the Nitzsche atlas (Nitzsche et al., 2019) and the Czeibert atlas (Czeibert et al., 2019) to the same template space using the affine + SyN nonlinear registration in ANTs. The Nitzsche atlas was used for large-area ROIs like entire lobes, while the Czeibert atlas was used for more specific subregions like the hippocampus. All resulting images were visually inspected for quality and rerun with new command line parameters when necessary (Fig. 1). Region-wise volumes were determined by warping the annotated atlas back to each individual's subject space and quantifying the number of voxels that made up each region of interest.

\section{Deriving diffusion metrics}

We calculated traditional tensor metrics [fractional anisotropy (FA) and mean diffusivity (MD)] using FSL (version 6.0.1; Jenkinson et al., 2012) and higher-order, multicompartment metrics [neurite density index (NDI), orientation dispersion index (ODI), and fractional isotropy (FISO)] using the NODDI (Zhang et al., 2012) model with the Microstructure Diffusion Toolbox (Harms et al., 2017). The traditional tensor metrics are widely used, but typically are applied only to white matter. NODDI metrics are tissue type agnostic and can readily be used in gray matter as it characterizes diffusion within each voxel as a combination of intracellular, extracellular, and CSF-based components. The intracellular compartment ostensibly captures neurite membranes and myelin sheaths and is modeled as a set of sticks with restricted diffusion perpendicular to the orientation of the axonal bundles and unhindered diffusion along them. The extracellular compartment is designed to model the space around the neurites, composed of glia and somas, as hindered Gaussian anisotropic diffusion. The CSF is modeled as isotropic diffusion. A summary of all the diffusion metrics used is provided in Table 1.

The hippocampus, parahippocampal gyrus, and prefrontal cortex (PFC) were selected as a priori regions because aging and $\mathrm{AD}$ present early changes in these regions in dogs (Shimada et al., 1992; Thal et al., 2002; Ezekiel et al., 2004; Su et al., 2005; Tapp et al., 2004, 2006; Hwang et al., 2008; Head, 2011). Region-specific averages were obtained by aligning the Czeibert atlas (Czeibert et al., 2019) to each subject's parametric maps. Diffusion metrics were then averaged across each region of interest using AFNI (Analysis of Functional NeuroImages; Cox, 1996). All statistical analyses were performed in Python Scipy (Jones et al., 2001; https://www.scipy.org) or GraphPad Prism 8.3.0. All regression analyses were simple linear regressions. The effects of interventions were assessed with ANOVA, and multiple comparisons were corrected using Holm-Sidak statistical hypothesis testing (Holm, 1979).

Whole-brain exploratory analysis was conducted to measure global longitudinal changes in each group separately using a paired $t$ test in a voxelwise manner using $3 \mathrm{dttest}++$ in AFNI. The AFNI clusterwise simulations (Forman et al., 1995) were used to correct for multiple comparisons. Parametric maps of each subject were passed in after they were registered to a common space, and a brain mask was passed in to improve power. To assess the interaction between intervention and time, a difference image was created (T0-T1) for each metric and each subject, and the difference images of each group were compared through an unpaired $t$ test. The -clustsim option was used to determine the minimum cluster threshold for each individual test to maintain a final $\alpha$ of 0.05 . 
Table 1. A description of the diffusion metrics used

\begin{tabular}{|c|c|c|c|}
\hline Metric & Abbreviation & Description & Range \\
\hline Fractional anisotropy & $\mathrm{FA}$ & $\begin{array}{l}\text { A measure of axonal organization or integrity based on the coherence of orientations of the } \\
\text { bundles. Mainly used to study white matter, and generally decreases with age. Reductions } \\
\text { in FA can mean neurodegeneration, a myelin sheath depletion, or just general atrophy of } \\
\text { fiber bundles (Song et al., 2003; Budde et al., 2007). FA reductions have also been associ- } \\
\text { ated with the accumulation of amyloid plaques (Tievsky et al., 1999; Wieshmann et al., } \\
\text { 1999; Kealey et al., 2004) }\end{array}$ & 0 (most isotropic) to 1 (least isotropic) \\
\hline Mean diffusivity & MD & $\begin{array}{l}\text { Another measure of white matter bundle integrity calculated as the average amount of water } \\
\text { diffusion inside the voxel. MD in most regions increases with age, also suggesting demye- } \\
\text { lination or axonal degradation (Abe et al., 2002; Grieve et al., 2007; Hsu et al., 2008) }\end{array}$ & $\begin{array}{l}\text { Continuous (directly proportional to the } \\
\text { amount of diffusion) }\end{array}$ \\
\hline Neurite density index & NDI & $\begin{array}{l}\text { Calculated as the proportion of the voxel expressing unhindered diffusion along a given set of } \\
\text { sticks, and restricted diffusion perpendicular to the same set of sticks. It measures intracel- } \\
\text { lular volume fraction and could detect inflammation as cell swelling results in increased } \\
\text { volume (Colgan et al., 2016; Garcia-Hernandez et al., 2020) }\end{array}$ & $\begin{array}{l}0 \text { (most extracellular) to } 1 \text { (most } \\
\text { intracellular) }\end{array}$ \\
\hline Orientation dispersion index & ODI & $\begin{array}{l}\text { A measure of tortuosity coupling an intracellular and extracellular space. Gives the variability } \\
\text { of neurite orientations, and might be able to pick up on the dispersion of axons and neu- } \\
\text { rons within a voxel (Billiet et al., 2015). May also be positively correlated with microglial } \\
\text { density (Colgan et al., 2016; Yi et al., 2019; Garcia-Hernandez et al., 2020) }\end{array}$ & 0 (least dispersed) to 1 (most dispersed) \\
\hline Fractional isotropy & FISO & $\begin{array}{l}\text { A measure of the amount of isotropic free volume within a voxel and is usually proportional } \\
\text { to the amount of CSF in a voxel. Might also pick up on other free water entities like dead } \\
\text { cells (Billiet et al., 2015) }\end{array}$ & 0 (least (SF) to 1 (most CSF) \\
\hline
\end{tabular}

A version of this table first appeared in Radhakrishnan et al. (2020).

Data availability

Code for data processing and analysis is available at https://github.com/ StarkLabUCI/Woofusion.

\section{Results}

The NDI of the beagle hippocampus and parahippocampal gyrus

increases with age

Our first question was whether diffusion within hippocampal and parahippocampal gray matter was affected by age. Previous work in our laboratory has shown that the NDI of the hippocampus as a whole (Venkatesh et al., 2020), and specifically the DG/CA3 subfields (Radhakrishnan et al., 2020), is higher in older humans (59-84 years of age) than young adults (20-38 years of age) and that this increase is nega-

tively correlated with memory performance (Radhakrishnan et al., 2020). Here, we found a similar relationship between age and hippocampal NDI at baseline, before treatment, in the canine model across all groups (simple linear regression: $R^{2}=0.111, p=0.031$; Fig. 2). Moreover, we observed a similar relationship between age and parahippocampal NDI $\left(R^{2}=0.131, p=0.018\right.$; Fig. 2$)$. This relationship between age and NDI was insignificant overall when averaging over the entire temporal lobe $\left(R^{2}=0.008, p=0.567\right)$, suggesting a focused change in these regions with age.

To determine whether these results were driven by gray matter or white matter voxels, we classified individual voxels in these regions into gray or white matter by FA thresholding. Those voxels with FA $>0.4$ were classified as likely white matter voxels, while those with $\mathrm{FA}<0.4$ were classified as likely gray matter voxels (Kumar et al., 2016). We found that the ratio of gray matter to white matter voxels was, on average, 7.48:1 in the hippocampus and 9.07:1 in the parahippocampal gyrus, suggesting that a clear majority of the signal we were detecting in these
ROIs was driven by gray matter. Moreover, removal of the white matter voxels from the regions of interest when averaging across the parametric maps did not significantly change the results.

None of the other studied metrics showed a reliable relationship with age in the hippocampus or the parahippocampal gyrus, further bolstering our claim that the NDI might be capturing unique aging-associated microstructural properties in hippocampal and parahippocampal gray matter not typically detected by simple tensor metrics. We found no significant differences in NDI between hemispheres in both regions. Our male/female distribution did not permit us to test for sex differences.

One year treatment with tacrolimus results in a decrease in hippocampal and parahippocampal NDI and an increase in parahippocampal ODI

Dogs treated with tacrolimus for a year had significantly lowered hippocampal NDI (repeated-measures ANOVA, Sidak multiplecomparisons test: $t=3.976, p=0.001, \mathrm{df}=25)$ and para- 

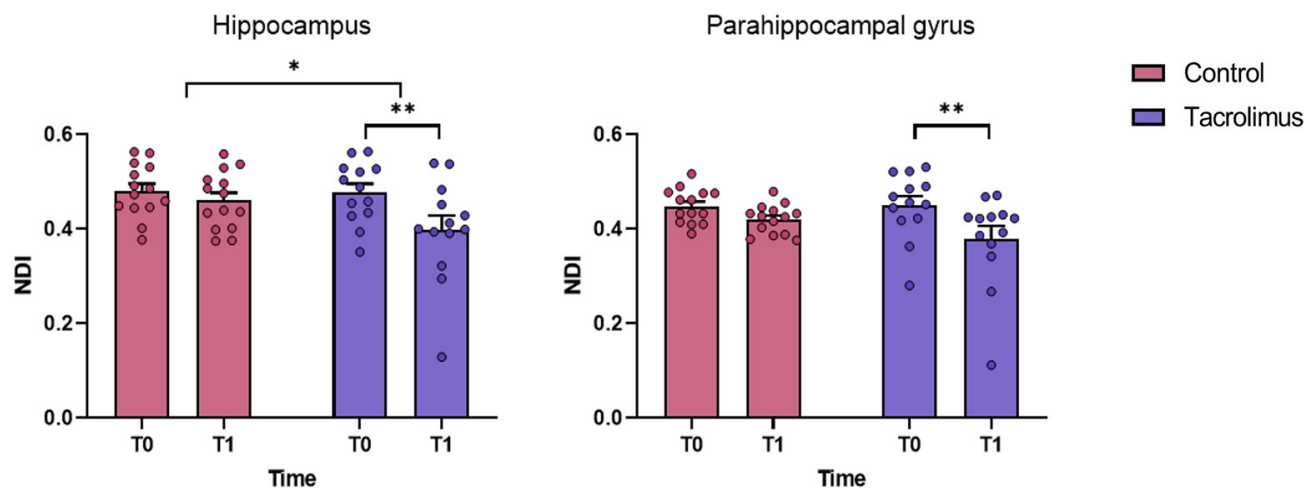

Figure 3. One year treatment with tacrolimus significantly reduces the NDI in both the hippocampus $(t=3.976, p=0.001)$ and the parahippocampal gyrus ( $t=3.711, p=0.002)$. There was a significant interaction between intervention and time in the hippocampus $(F=4.482, p=0.044$, ANOVA), but not in the parahippocampal gyrus $(F=2.579, p=0.120)$. Error bars show the SEM.

hippocampal NDI $(t=3.711, p=0.002$, $\mathrm{df}=25)$ NDI compared with baseline, suggesting that the drug might be rescuing some level of age-associated change (Fig. 3). Such a change was not observed between the time points for the control dogs in either of the regions. Though the dogs are not old enough to be exhibiting significant cognitive deficits (Milgram, 2003), previous studies in humans using structural equation modeling show that increased hippocampal NDI mediates age-related cognitive decline (Radhakrishnan et al., 2020), indicating that the drug may have the potential to protect against cognitive deficits if administered for a longer period of time.

The parahippocampal ODI significantly increased after a year in the control dogs $(t=3.197, p=0.007)$, but not in the dogs treated with tacrolimus $(t=0.082, p=0.995)$. We also observed a critical interaction between drug and time on ODI $(F=4.660, p=0.040$, ANOVA). We did not notice any correlations between parahippocampal ODI and age at baseline $\left(R^{2}=0.039, p=0.805\right.$; Fig. 4$)$, possibly because the dogs are middle aged, and we have a relatively restricted range. However, age-related increases in ODI have been reported in human studies with negative consequences (Nazeri et al., 2015; Mole et al., 2020; Venkatesh et al., 2020).

As with the previous analysis, removal of the white matter voxels from the regions of interest when averaging across the parametric maps did not significantly change the results. No other studied metric showed an effect of time or intervention in these regions. We found no significant difference in the diffusion metrics between hemispheres for all regions studied.

\section{Tacrolimus protects against structural changes in the prefrontal cortex}

We next turned to changes outside of the hippocampal region. One of the first regions to be affected in the aging canine brain is the PFC. MRI studies have shown that the PFC starts reducing in volume at an earlier age (8-11 years) compared with the hippocampus (Tapp et al., 2004). Cognitively, aging also leads to poorer performance on tasks associated with the PFC, like reversal learning and visuospatial memory (Head et al., 1998; Tapp et al., 2003; Studzinski et al., 2006). While it is unclear whether the prefrontal cortex is an early region affected by age-related neuroinflammation, it is one of the first areas in the canine brain to develop plaques (Wieshmann et al., 1999; Bosch et al., 2012). Formation of these plaques has consistently been reflected in diffusion MRI studies as a reduction of fractional anisotropy (Tievsky et al., 1999; Wieshmann et al., 1999; Kealey et al., 2004). It is not very surprising that we found no significant relationship between age and prefrontal NDI or ODI at baseline (NDI: $R^{2}=$ $0.001, p=0.806$; ODI: $R^{2}=0.006, p=0.608$ ), and these metrics did not significantly change in either group over the year. However, despite the lack of a significant relationship between age and prefrontal FA at baseline $\left(R^{2}=0.015, p=0.440\right)$, it decreased in the control dogs after a year $(t=5.042, p<0.001)$. This observation is directly analogous to the negative correlation between age and FA consistently observed in humans (Bennett et al., 2010; Kantarci et al., 2013). Interestingly, prefrontal FA did not decrease in the dogs treated with tacrolimus for a year $(t=1.890, p=0.135)$, suggesting that the drug may be preventing age-associated structural deterioration in the prefrontal cortex (Fig. 5). The lack of a cross-sectional relationship with age at 


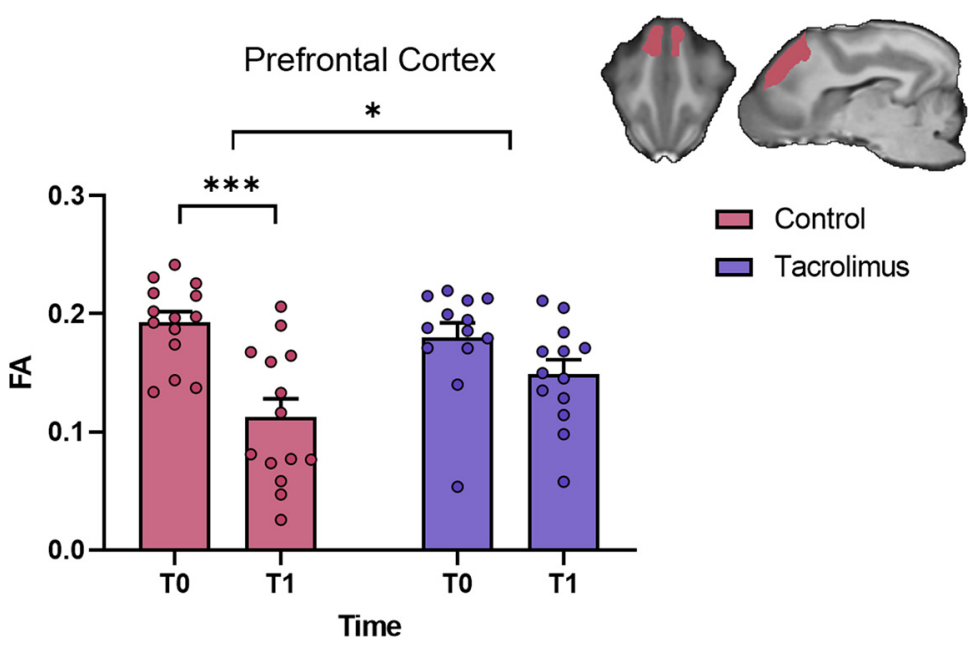

Figure 5. After 1 year, FA significantly reduced in the prefrontal cortex of the control dogs $(t=5.042$, $p<0.0001)$, but not in the dogs treated with tacrolimus $(t=1.890, p=0.135)$. The interaction between intervention and time was also significant $(F=4.568, p=0.042$, ANOVA). Error bars show the SEM.

baseline might be attributed to individual differences and the dogs not being old enough to exhibit clear differences.

We also segmented the PFC into white matter and gray matter regions, as described in the The NDI of the beagle hippocampus and parahippocampal gyrus increases with age subsection. We found that the ratio of gray matter to white matter voxels was, on average, $60.55: 1$, showing that an overwhelming majority of the signal was driven by gray matter. Removal of the white matter voxels from the regions of interest when averaging across the parametric maps did not significantly change the results. No other studied metric showed an effect of time or intervention in these regions. All effects reported were bilateral. Our male/female distribution did not permit us to test for sex differences.

\section{Whole-brain exploratory analysis revealed disorganized decreases in white matter of the control dogs, but not of the dogs treated with tacrolimus}

Following these a priori regional analyses, we conducted a whole-brain exploratory analysis to determine whether these changes were unique to these areas or whether they were found previously as well. Voxelwise comparisons were performed in a pairwise manner for each dog in both groups using the AFNI $3 \mathrm{dttest}++$. We used the -clustsim option to determine the minimum cluster threshold to ensure an false discovery rate-corrected $p$ value of at least 0.05 , with an $\alpha$ of 0.05 . We observed a disorganized, but large-scale, decrease in FA in many white matter regions (Fig. 6; 59,207 voxels survived thresholding) only in the control dogs. This was not unexpected, as the loss of white matter integrity is a classic hallmark of aging (Vernooij et al., 2008; Bennett et al., 2010; Madden et al., 2012). The dogs treated with tacrolimus did not show this same decrease (no voxels survived thresholding), further suggesting that the drug may be protecting against even sporadic neurodegeneration. However, these results should be interpreted cautiously as we found no significant interaction between intervention and time at our chosen thresholds [i.e., no voxels survived thresholding when comparing the difference image in time ( $\mathrm{T} 0$ - T1) between the two groups].

Interestingly, no other diffusion metric studied exhibited reliable differences over time in either group, suggesting a very specific age-related decrease in the control dogs in only the a priori regions and a distinct protection against this effect by the drug.
This finding bolsters our theory that NDI and ODI are sensitive to specific microstructural changes associated with age, and may be early predictors of medial temporal lobe pathology in these specific regions.

\section{The hippocampal volume of both groups decreased over time, but not in the other a priori regions}

We observed no significant relationship between age and hippocampal or parahippocampal volume at baseline as measured by the T1w image (hippocampus: $R^{2}=0.003, p=0.771$; parahippocampal gyrus: $R^{2}=0.027, p=0.404$ ), further demonstrating that these diffusion metrics may be detecting microstructural changes well before more large-scale volumetric changes present themselves. However, we observed a main effect of time on hippocampal volume for both groups $(F=9.986, p=0.0041$, ANOVA), suggesting that while the drug may protect against specific cytoarchitectural changes, it may not be able to protect against overall age-related volumetric atrophy in the hippocampus. As expected, no cross-sectional relationship between age and prefrontal volume was observed at baseline, and prefrontal volume did not change over the year in either group. There was also no global reduction in volume in either group, suggesting that age-associated atrophy is limited to the hippocampus at this stage in the life span. These results support the theory that volumetric changes in these regions occur further down the life span and that diffusion metrics may be earlier indicators of future pathologic and cognitive decline and may be more sensitive to measure interventional changes.

\section{Limited cognitive changes were observed over time}

We also assessed the effect of age on baseline cognition as well as the interaction between intervention and cognition after a year. We observed no significant relationship between age and discrimination learning $\left(R^{2}=0.014, p=0.442\right)$ or reversal learning $\left(R^{2}=0.017, p=0.393\right)$. However, age had a negative effect on spatial accuracy at $20 \mathrm{~s}\left(R^{2}=0.172, p=0.007\right)$ and spatial accuracy at $70 \mathrm{~s}\left(R^{2}=0.109, p=0.036\right)$, but not with spatial accuracy at $110 \mathrm{~s}\left(R^{2}=0.045, p=0.186\right)$. After 1 year of intervention, there was no significant difference in either group with respect to discrimination learning (control, $p=0.821$; tacrolimus, $p=0.628$ ) or spatial accuracy (control: $p=0.151,0.796,0.504$; tacrolimus: $p=0.999,0.471,0.625$ for 20,70 , and $110 \mathrm{~s}$ accuracy versions, respectively). Performance on reversal learning trended toward a decrease in error scores (i.e., better function) over time in the control dogs $(p=0.057)$, but not in the dogs treated with tacrolimus $(p=0.112)$. After the removal of an outlier in the tacrolimus group, this effect of time was significant in both groups (control, $p=0.041$; tacrolimus, $p=0.029$ ). These data, in conjunction, suggest that while these dogs are not exhibiting major cognitive decline, continued treatment will allow for more opportunities to see improvements. To that end, continued treatment may also be able to reveal whether the structural protection that tacrolimus grants to the study group translates to cognitive benefits as well. None of the cognitive scores studied were significantly correlated with the diffusion metrics, possibly because the middle-aged dogs do not yet show significant decline but are already displaying signs of microstructural deterioration. 


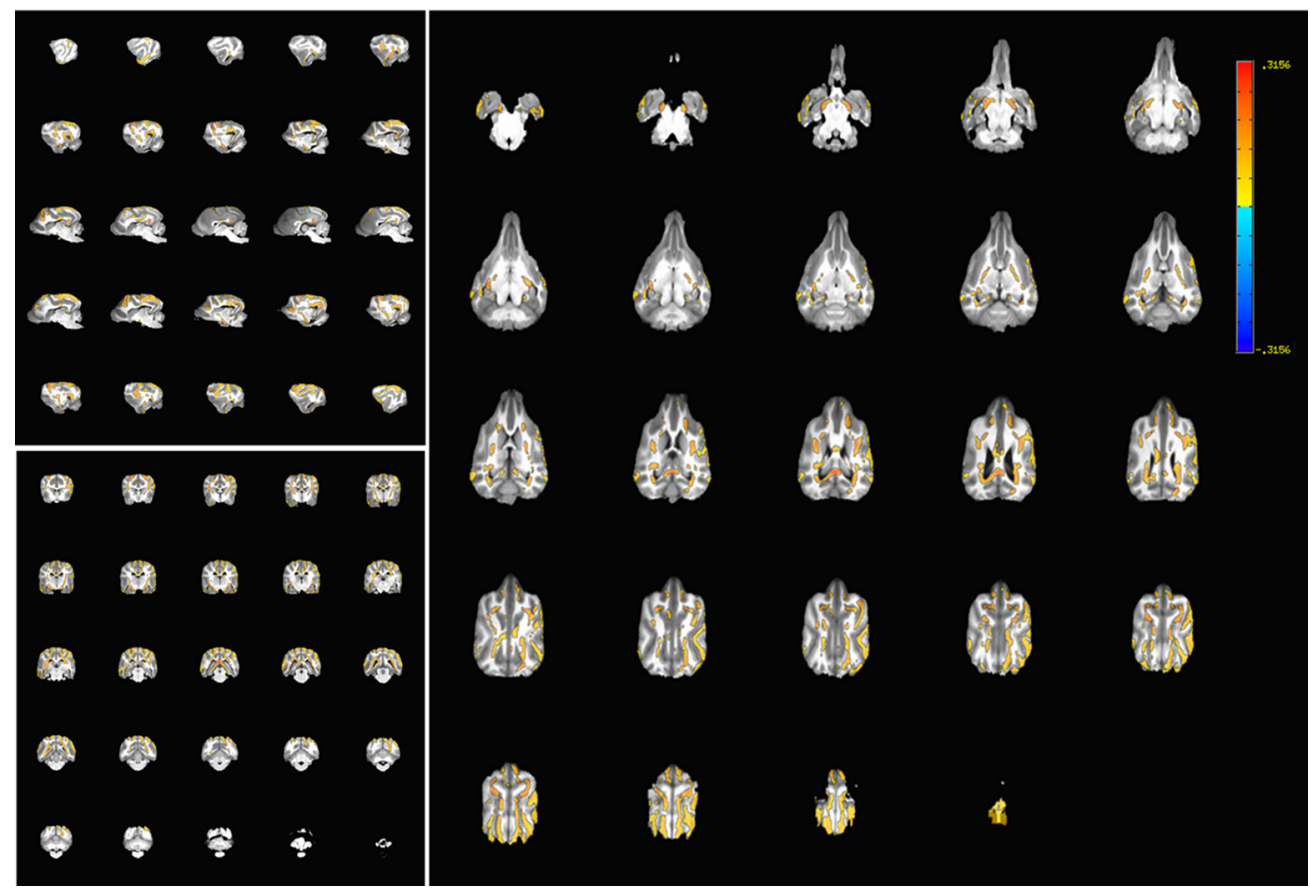

Figure 6. Difference in $\mathrm{T} 0$ - T1 in FA of the control dogs. We found significant decreases in white matter FA after 1 year in control dogs, but not in the tacrolimus-treated dogs. Colored regions show regions where the FA at T0 was significantly different from the FA at T1 for control dogs (red-yellow, T0 > T1; teal-blue, T0 < T1). Dogs treated with tacrolimus are not pictured here as there were no significant voxels of difference when comparing the two time points.

\section{Discussion}

In this study, we used the drug tacrolimus to test the hypothesis that calcineurin inhibitors can prevent aging-related pathology, as measured by neuroimaging, in the middleaged canine. We observed a positive correlation between hippocampal and parahippocampal NDI with age at baseline, a relationship that agreed with our observations in humans from previous studies (Radhakrishnan et al., 2020; Venkatesh et al., 2020). Interestingly, 1 year treatment with tacrolimus resulted in a decrease in both hippocampal and parahippocampal NDI, while the control dogs did not exhibit this effect. The drug also protected against an increase in parahippocampal ODI and a decrease in prefrontal FA, both consistently recognized as negative consequences of aging. We also showed that these changes precede most widespread volumetric changes and all cognitive changes and are specific to the a priori regions studied. These data, put together, suggest that (1) calcineurin inhibitors may rescue negative microstructural outcomes associated with age and (2) advanced diffusion imaging measures may be valuable biomarkers for predicting aging-associated pathology well before other symptoms are present.

The overexpression of calcineurin helps drive neuroinflammation and astrogliosis, which are commonly observed in aging (Rusnak and Mertz, 2000; Norris et al., 2005; Reese and Taglialatela, 2011). Although neuroinflammation is ultimately a systemic consequence of age, the dogs we studied are not old enough to exhibit these changes globally (subsection Wholebrain exploratory analysis revealed disorganized decreases in white matter of the control dogs, but not of the dogs treated with tacrolimus). However, the hippocampus and nearby regions are thought to be some of the initial hotspots of such inflammation (Akiyama et al., 2000; Verbitsky et al., 2004; Gavilán et al., 2007; Head, 2011), which could potentially be captured in our middleaged model. Older dogs display an increase in GFAP immunoreactivity and protein levels in the hippocampus and neighboring regions, as well as increased astrogliosis and astrocyte hypertrophy (Borràs et al., 1999; Pugliese et al., 2006; Hwang et al., 2008). While there are currently no effective methods to measure such inflammatory changes noninvasively, several mouse studies have demonstrated reliable positive correlations between both the NDI and the ODI with immunoreactivity, astrocyte reactivity, and microglia count (Colgan et al., 2016; Grussu et al., 2017; Wang et al., 2019). Here, we showed that tacrolimus reduces hippocampal and parahippocampal NDI after just a year of treatment. Though neuropathological outcomes have not yet been obtained, increases in NDI in gray matter regions could be a consequence of inflammation, as microglial and astrocyte swelling cause the cells to expand, resulting in an increase in intracellular volume fraction, which is estimated by NDI (Colgan et al., 2016; Garcia-Hernandez et al., 2020). The hypothesis that tacrolimus may prevent neuroinflammation is further supported by our finding that it protects against an increase in parahippocampal ODI, which could be a marker for microglial density (Colgan et al., 2016; Yi et al., 2019; Garcia-Hernandez et al., 2020). Region-specific increases in microglial densities in the hippocampus and parahippocampal regions also precede plaque formation and are suppressed in mouse models of AD by inhibition of calcineurin signaling pathways (Furman et al., 2012; Sompol and Norris, 2018), again suggesting that tacrolimus administration in dogs may be protecting against aging-related pathologic changes through calcineurin inhibition (Marlatt et al., 2014; Fakhoury, 2018). However, these theories must be handled cautiously, as we are yet to find adequate histologic evidence for the neurobiological specificity of NODDI metrics.

We also found that tacrolimus protects against an age-associated decrease in prefrontal FA, suggesting that the drug may be capable of preventing, or at least delaying, the formation of amyloid plaques (Andrews-Hanna et al., 2007; 
Kantarci et al., 2017; Nasrabady et al., 2018), which, again, is consistent with the effects of calcineurin inhibition in rodent models (Hong et al., 2010). Moreover, the dogs showed no adverse effects on kidney function as a consequence of the drug, as measured by BUN, creatine, and phosphorous levels in the blood, reducing concerns that tacrolimus might cause nephrotoxicity in this model.

Perhaps most striking is the fact that these effects are specific to the prefrontal and hippocampal regions in both groups of dogs. Other than the drug protecting against global neurodegeneration in white matter (reflected as a decrease in FA in the control dogs, but not those treated with tacrolimus), the diffusion metrics in no other brain regions, except those considered a priori aging hotspots, changed after a year. This specificity and the fact that these protections are displayed before cognitive decline is promising. These results strongly support the potential of tacrolimus to prevent age-related pathologic decline and suggest that similar drugs could be used as middle-aged preventative care in humans. More research on the neurobiological mechanisms of calcineurin inhibitors would help to indicate a more specific time frame in the human life span in which these drugs could be most effective in preventing neuropathology.

The results from this study also suggest a compelling case for using higher-order diffusion imaging measures. NDI, ODI, and even tensor metrics like FA computed on multishell data, all show potential to be early biomarkers for aging-related pathology. They may be sensitive to microstructural alterations preceding other measurable pathologies and capture these changes well before gross atrophy or cognitive decline is present. Acquisition of higher-order, multishell data allows for both forms of analyses, and the complexity and the tissue-agnostic approach of NODDI (Zhang et al., 2012) makes it far more applicable to the study of gray matter microstructure and longitudinal change that may result from $\mathrm{AD}$-associated neuropathological changes (e.g., inflammation and astrogliosis).

This study provides novel outcomes that include (1) evidence for treatment benefits of tacrolimus on brain structure before cognitive decline; and (2) support for a canine model that shows changes in NODDI metrics that can be detected both in both cross-sectional and longitudinal studies. However, this study is not without limitations. The advanced diffusion metrics, specifically NDI and ODI, have not been adequately histologically validated, and though some studies suggest that they might be sensitive to inflammation, these results must be interpreted cautiously. The male/female ratio prevents us from assessing sex differences, and these results may not be as significant in male beagles. However, all male dogs studied had diffusion metrics well within the range of their female counterparts, with no significant outliers. Moreover, dogs were middle aged without signs of significant cognitive decline, posing a challenge to detect structure-behavior relationships. Unfortunately, both groups showed a significant decrease in hippocampal volume after 1 year, suggesting that the drug may not be able to protect against more macrostructural atrophy. The study will continue for another year, and our hypothesis that structural brain changes occur before cognitive decline may be testable at the next time point. Also, future neuropathology outcome measures will help us determine whether our speculations regarding FA and $\mathrm{A} \beta$, and NDI and glial activation/inflammation are valid.

In summary, treatment with low doses of tacrolimus in the canine model of aging protects against age-associated structural changes, as shown by neuroimaging and presents no observable adverse effects. It is intriguing to consider that the structural neuroimaging outcomes noted here may precede cognitive decline in control dogs and may predict benefits in treated animals, which will be evaluated as the study continues.

\section{References}

Abdul HM, Sama MA, Furman JL, Mathis DM, Beckett TL, Weidner AM, Patel ES, Baig I, Murphy MP, LeVine H, Kraner SD, Norris CM (2009) Cognitive decline in Alzheimer's disease is associated with selective changes in calcineurin/NFAT signaling. J Neurosci 29:12957-12969.

Abe O, Aoki S, Hayashi N, Yamada H, Kunimatsu A, Mori H, Yoshikawa T, Okubo T, Ohtomo K (2002) Normal aging in the central nervous system: quantitative MR diffusion-tensor analysis. Neurobiol Aging 23:433-441.

Akiyama H, Barger S, Barnum S, Bradt B, Bauer J, Cole GM, Cooper NR, Eikelenboom P, Emmerling M, Fiebich BL, Finch CE, Frautschy S, Griffin WS, Hampel H, Hull M, Landreth G, Lue L, Mrak R, Mackenzie IR, McGeer PL, Wyss-Coray T (2000) Inflammation and Alzheimer's disease. Neurobiol Aging 21:383-421.

Andersson JLR, Sotiropoulos SN (2016) An integrated approach to correction for off-resonance effects and subject movement in diffusion MR imaging. Neuroimage 125:1063-1078.

Andrews-Hanna JR, Snyder AZ, Vincent JL, Lustig C, Head D, Raichle ME, Buckner RL (2007) Disruption of large-scale brain systems in advanced aging. Neuron 56:924-935.

Basser PJ, Mattiello J, LeBihan D (1994) MR diffusion tensor spectroscopy and imaging. Biophys J 66:259-267.

Bennett IJ, Madden DJ, Vaidya CJ, Howard DV, Howard JJ (2010) Age-related differences in multiple measures of white matter integrity: a diffusion tensor imaging study of healthy aging. Hum Brain Mapp 31:378-390.

Billiet T, Vandenbulcke M, Mädler B, Peeters R, Dhollander T, Zhang H, Deprez S, Van den Bergh BRH, Sunaert S, Emsell L (2015) Age-related microstructural differences quantified using myelin water imaging and advanced diffusion MRI. Neurobiol Aging 36:2107-2121.

Borràs D, Ferrer I, Pumarola M (1999) Age-related changes in the brain of the dog. Vet Pathol 36:202-211.

Bosch MN, Pugliese M, Gimeno-Bayón J, Rodríguez MJ, Mahy N (2012) Dogs with cognitive dysfunction syndrome: a natural model of Alzheimer's disease. Curr Alzheimer Res 9:298-314.

Budde MD, Kim JH, Liang H-F, Schmidt RE, Russell JH, Cross AH, Song S$\mathrm{K}$ (2007) Toward accurate diagnosis of white matter pathology using diffusion tensor imaging. Magn Reson Med 57:688-695.

Christie L-A, Studzinski CM, Araujo JA, Leung CSK, Ikeda-Douglas CJ, Head E, Cotman CW, Milgram NW (2005) A comparison of egocentric and allocentric age-dependent spatial learning in the beagle dog. Prog Neuropsychopharmacol Biol Psychiatry 29:361-369.

Chua TC, Wen W, Slavin MJ, Sachdev PS (2008) Diffusion tensor imaging in mild cognitive impairment and Alzheimer's disease: a review. Curr Opin Neurol 21:83-92.

Colgan N, Siow B, O'Callaghan JM, Harrison IF, Wells JA, Holmes HE, Ismail O, Richardson S, Alexander DC, Collins EC, Fisher EM, Johnson R, Schwarz AJ, Ahmed Z, O’Neill MJ, Murray TK, Zhang H, Lythgoe MF (2016) Application of neurite orientation dispersion and density imaging (NODDI) to a tau pathology model of Alzheimer's disease. Neuroimage 125:739-744.

Cox RW (1996) AFNI: software for analysis and visualization of functional magnetic resonance neuroimages. Comput Biomed Res 29:162-173.

Czeibert K, Andics A, Petneházy Ö, Kubinyi E (2019) A detailed canine brain label map for neuroimaging analysis. Biologia Futura 70:112-120.

Dalgaard L (2015) Comparison of minipig, dog, monkey and human drug metabolism and disposition. J Pharmacol Toxicol Methods 74:80-92.

Datta R, Lee J, Duda J, Avants BB, Vite CH, Tseng B, Gee JC, Aguirre GD, Aguirre GK (2012) A Digital Atlas of the Dog Brain. PLoS One 7:e52140.

Dos Santos Picanco LC, Ozela PF, de Fatima de Brito M, Pinheiro AA, Padilha EC, Braga FS, de Paula da Silva CHT, Dos Santos CBR, Rosa JMC, da Silva Hage-Melim LI (2018) Alzheimer's disease: a review from the pathophysiology to diagnosis, new perspectives for pharmacological treatment. Curr Med Chem 25:3141-3159.

Ezekiel F, Chao L, Kornak J, Du A-T, Cardenas V, Truran D, Jagust W, Chui H, Miller B, Yaffe K, Schuff N, Weiner M (2004) Comparisons between global and focal brain atrophy rates in normal aging and Alzheimer disease: boundary shift integral versus tracing of the entorhinal cortex and hippocampus. Alzheimer Dis Assoc Disord 18:196-201. 
Fakhoury M (2018) Microglia and astrocytes in Alzheimer's disease: implications for therapy. Curr Neuropharmacol 16:508-518.

Forestier A, Douki T, De Rosa V, Béal D, Rachidi W (2015) Combination of $\mathrm{A} \beta$ secretion and oxidative stress in an Alzheimer-like cell line leads to the over-expression of the nucleotide excision repair proteins DDB2 and XPC. Int J Mol Sci 16:17422-17444.

Forman SD, Cohen JD, Fitzgerald M, Eddy WF, Mintun MA, Noll DC (1995) Improved assessment of significant activation in functional magnetic resonance imaging (fMRI): use of a cluster-size threshold. Magn Reson Med 33:636-647.

Furman JL, Sama DM, Gant JC, Beckett TL, Murphy MP, Bachstetter AD, Van Eldik LJ, Norris CM (2012) Targeting astrocytes ameliorates neurologic changes in a mouse model of Alzheimer's disease. J Neurosci 32:16129-16140.

Garcia-Hernandez R, Carpena AT, Drakesmith M, Koller K, Jones DK, Canals S, Santis SD (2020) Imaging microglia and astrocytes non-invasively using diffusion MRI. bioRxiv 938910.

Gavilán MP, Revilla E, Pintado C, Castaño A, Vizuete ML, Moreno-González I, Baglietto-Vargas D, Sánchez-Varo R, Vitorica J, Gutiérrez A, Ruano D (2007) Molecular and cellular characterization of the age-related neuroinflammatory processes occurring in normal rat hippocampus: potential relation with the loss of somatostatin GABAergic neurons. J Neurochem 103:984-996.

Grieve SM, Williams LM, Paul RH, Clark CR, Gordon E (2007) Cognitive aging, executive function, and fractional anisotropy: a diffusion tensor MR imaging study. AJNR Am J Neuroradiol 28:226-235.

Grussu F, Schneider T, Tur C, Yates RL, Tachrount M, Ianuş A, Yiannakas MC, Newcombe J, Zhang H, Alexander DC, DeLuca GC, Gandini Wheeler-Kingshott CAM (2017) Neurite dispersion: a new marker of multiple sclerosis spinal cord pathology? Ann Clin Transl Neurol 4:663-679.

Hardy JA, Higgins GA (1992) Alzheimer's disease: the amyloid cascade hypothesis. Science 256:184-186.

Harms RL, Fritz FJ, Tobisch A, Goebel R, Roebroeck A (2017) Robust and fast nonlinear optimization of diffusion MRI microstructure models. NeuroImage 155:82-96.

Head E (2011) Neurobiology of the aging dog. Age (Dordr) 33:485-496.

Head E, Callahan H, Muggenburg BA, Cotman CW, Milgram NW (1998) Visual-discrimination learning ability and beta-amyloid accumulation in the dog. Neurobiol Aging 19:415-425.

Head E, Pop V, Vasilevko V, Hill M, Saing T, Sarsoza F, Nistor M, Christie L-A, Milton S, Glabe C, Barrett E, Cribbs D (2008) A two-year study with fibrillar $\beta$-amyloid $(\mathrm{A} \beta)$ immunization in aged canines: effects on cognitive function and brain $\mathrm{A} \beta$. J Neurosci 28:3555-3566.

Hendrie HC, Hake A, Lane K, Purnell C, Unverzagt F, Smith-Gamble V, Murrell J, Ogunniyi A, Baiyewu O, Callahan C, Saykin A, Taylor S, Hall K, Gao S (2015) Statin use, incident dementia and Alzheimer disease in elderly African Americans. Ethn Dis 25:345-354.

Hoffman JM, Creevy KE, Franks A, O'Neill DG, Promislow DEL (2018) The companion dog as a model for human aging and mortality. Aging Cell 17:e12737.

Holm S (1979) A simple sequentially rejective multiple test procedure. Scand J Stat 6:65-70.

Holtzman DM, John CM, Goate A (2011) Alzheimer's disease: the challenge of the second century. Sci Transl Med 3:77sr1.

Hong H-S, Hwang J-Y, Son S-M, Kim Y-H, Moon M, Inhee M-J (2010) FK506 reduces amyloid plaque burden and induces MMP-9 in A $\beta$ PP/ PS1 double transgenic mice. J Alzheimers Dis 22:97-105.

Hsu J-L, Leemans A, Bai C-H, Lee C-H, Tsai Y-F, Chiu H-C, Chen W-H (2008) Gender differences and age-related white matter changes of the human brain: a diffusion tensor imaging study. Neuroimage 39:566-577.

Hudry E, Wu H-Y, Arbel-Ornath M, Hashimoto T, Matsouaka R, Fan Z, Spires-Jones TL, Betensky RA, Bacskai BJ, Hyman BT (2012) Inhibition of the NFAT pathway alleviates amyloid $\beta$ neurotoxicity in a mouse model of Alzheimer's disease. J Neurosci 32:3176-3192.

Hwang IK, Choi JH, Li H, Yoo K-Y, Kim DW, Lee CH, Yi SS, Seong JK, Lee IS, Yoon YS, Won M-H (2008) Changes in glial fibrillary acidic protein immunoreactivity in the dentate gyrus and hippocampus proper of adult and aged dogs. J Vet Med Sci 70:965-969.

Inouye K, Pedrazzani ES, Pavarini SCI (2010) Alzheimer's disease influence on the perception of quality of life from the elderly people. Rev Esc Enferm USP 44:1093-1099.
Jenkinson M, Beckmann CF, Behrens TEJ, Woolrich MW, Smith SM (2012) FSL. Neuroimage 62:782-790

Jones E, Oliphant T, Peterson P (2001) SciPy: open source scientific tools for Python. Austin, TX: SciPy.

Kantarci K, Weigand SD, Przybelski SA, Preboske GM, Pankratz VS, Vemuri P, Senjem ML, Murphy MC, Gunter JL, Machulda MM, Ivnik RJ, Roberts RO, Boeve BF, Rocca WA, Knopman DS, Petersen RC, Jack CJ (2013) MRI and MRS predictors of mild cognitive impairment in a population-based sample. Neurology 81:126-133.

Kantarci K, Murray ME, Schwarz CG, Reid R, Przybelski SA, Lesnick T, Zuk SM, Raman MR, Senjem ML, Gunter JL, Boeve BF, Knopman DS, Parisi JE, Petersen RC, Jack CR, Dickson D (2017) White matter integrity on DTI and the pathologic staging of Alzheimer's disease. Neurobiol Aging 56:172-179.

Kealey SM, Kim Y, Provenzale JM (2004) Redefinition of multiple sclerosis plaque size using diffusion tensor MRI. Am J Roentgenol 183:497-503.

Kellner E, Dhital B, Kiselev VG, Reisert M (2016) Gibbs-ringing artifact removal based on local subvoxel-shifts. Magn Reason Med 76:1574-1581.

Kumar A, Singh N (2017) Calcineurin inhibitors improve memory loss and neuropathological changes in mouse model of dementia. Pharmacol Biochem Behav 153:147-159.

Kumar M, Duda J, Yoon S, Bagel J, O’Donnell P, Vite C, Pickup S, Gee J, Wolfe J, Poptani H (2016) Diffusion tensor imaging for assessing brain gray and white matter abnormalities in a feline model of $\alpha$-mannosidosis. J Neuropathol Exp Neurol 75:35-43.

Liu F, Grundke-Iqbal I, Iqbal K, Oda Y, Tomizawa K, Gong C-X (2005) Truncation and activation of calcineurin A by calpain I in Alzheimer disease brain. J Biol Chem 280:37755-37762.

Liu J, Liu Z, Zhang Y, Yin F (2015) A novel antagonistic role of natural compound icariin on neurotoxicity of amyloid $\beta$ peptide. Indian J Med Res 142:190-195.

Madden DJ, Bennett IJ, Burzynska A, Potter GG, Chen NK, Song AW (2012) Diffusion tensor imaging of cerebral white matter integrity in cognitive aging. Biochim Biophys Acta 1822:386-400.

Malleret G, Haditsch U, Genoux D, Jones MW, Bliss TV, Vanhoose AM, Weitlauf C, Kandel ER, Winder DG, Mansuy IM (2001) Inducible and reversible enhancement of learning, memory, and long-term potentiation by genetic inhibition of calcineurin. Cell 104:675-686.

Mansuy IM (2003) Calcineurin in memory and bidirectional plasticity. Biochem Biophys Res Commun 311:1195-1208.

Margarit C, Rimola A, Gonzalez-Pinto I, Cuervas-Mons V, Edo A, Andreu H, Moreno-Gonzalez E, Calleja JL (1998) Efficacy and safety of oral lowdose tacrolimus treatment in liver transplantation. Transpl Int 11 [Suppl 1]:S260-S266.

Marlatt MW, Bauer J, Aronica E, van Haastert ES, Hoozemans JJM, Joels M, Lucassen PJ (2014) Proliferation in the Alzheimer hippocampus is due to microglia, not astroglia, and occurs at sites of amyloid deposition. Neural Plast 2014:693851.

Milgram NW (2003) Cognitive experience and its effect on age-dependent cognitive decline in beagle dogs. Neurochem Res 28:1677-1682.

Milgram NW, Adams B, Callahan H, Head E, Mackay B, Thirlwell C, Cotman CW (1999) Landmark discrimination learning in the dog. Learn Mem 6:54-61.

Milgram NW, Zicker SC, Head E, Muggenburg BA, Murphey H, IkedaDouglas CJ, Cotman CW (2002) Dietary enrichment counteracts age-associated cognitive dysfunction in canines. Neurobiol Aging 23:737-745.

Mohmmad Abdul H, Baig I, Levine H, Guttmann RP, Norris CM (2011) Proteolysis of calcineurin is increased in human hippocampus during mild cognitive impairment and is stimulated by oligomeric Abeta in primary cell culture. Aging Cell 10:103-113.

Mole JP, Fasano F, Evans J, Sims R, Kidd E, Aggleton JP, Metzler-Baddeley C (2020) APOE- $\varepsilon 4$-related differences in left thalamic microstructure in cognitively healthy adults. Sci Rep 10:19787.

Nasrabady SE, Rizvi B, Goldman JE, Brickman AM (2018) White matter changes in Alzheimer's disease: a focus on myelin and oligodendrocytes. Acta Neuropathol Commun 6:22.

Nazeri A, Chakravarty MM, Rotenberg DJ, Rajji TK, Rathi Y, Michailovich OV, Voineskos AN (2015) Functional consequences of neurite orientation dispersion and density in humans across the adult lifespan. J Neurosci 35:1753-1762.

Nitzsche B, Boltze J, Ludewig E, Flegel T, Schmidt MJ, Seeger J, Barthel H, Brooks OW, Gounis MJ, Stoffel MH, Schulze S (2019) A stereotaxic 
breed-averaged, symmetric $\mathrm{T} 2 \mathrm{w}$ canine brain atlas including detailed morphological and volumetrical data sets. Neuroimage 187:93-103.

Norris CM, Kadish I, Blalock EM, Chen K-C, Thibault V, Porter NM, Landfield PW, Kraner SD (2005) Calcineurin triggers reactive/inflammatory processes in astrocytes and is upregulated in aging and Alzheimer's models. J Neurosci 25:4649-4658.

Pahnke J, Walker LC, Scheffler K, Krohn M (2009) Alzheimer's disease and blood-brain barrier function-why have anti- $\beta$-amyloid therapies failed to prevent dementia progression? Neurosci Biobehav Rev 33:1099-1108.

Patronek GJ, Waters DJ, Glickman LT (1997) Comparative longevity of pet dogs and humans: implications for gerontology research. J Gerontol A Biol Sci Med Sci 52:B171-B178.

Perl DP (2010) Neuropathology of Alzheimer's disease. Mt Sinai J Med 77:32-42.

Prpar Mihevc S, Majdič G (2019) Canine cognitive dysfunction and Alzheimer's disease-two facets of the same disease? Front Neurosci 13:604.

Pugliese M, Geloso MC, Carrasco JL, Mascort J, Michetti F, Mahy N (2006) Canine cognitive deficit correlates with diffuse plaque maturation and $\mathrm{S} 100 \beta$ (-) astrocytosis but not with insulin cerebrospinal fluid level. Acta Neuropathol 111:519.

Radhakrishnan H, Stark SM, Stark CEL (2020) Microstructural alterations in hippocampal subfields mediate age-related memory decline in humans. Front. Aging Neurosci 12:94.

Raffelt D, Tournier J-D, Rose S, Ridgway GR, Henderson R, Crozier S, Salvado O, Connelly A (2012) Apparent fibre density: a novel measure for the analysis of diffusion-weighted magnetic resonance images. Neuroimage 59:3976-3994.

Randhawa P, Starzl T, Demetris A (1997) Tacrolimus (FK506)-Associated Renal Pathology. Adv Anat Pathol 4:265.

Reese LC, Taglialatela G (2011) A role for calcineurin in Alzheimer's disease. Curr Neuropharmacol 9:685-692.

Reese LC, Zhang W, Dineley KT, Kayed R, Taglialatela G (2008) Selective induction of calcineurin activity and signaling by oligomeric amyloid beta. Aging Cell 7:824-835.

Reitz C, Mayeux R (2014) Alzheimer disease: epidemiology, diagnostic criteria, risk factors and biomarkers. Biochem Pharmacol 88:640-651.

Rojanathammanee L, Floden AM, Manocha GD, Combs CK (2015) Attenuation of microglial activation in a mouse model of Alzheimer's disease via NFAT inhibition. J Neuroinflammation 12:42.

Rozkalne A, Hyman BT, Spires-Jones TL (2011) Calcineurin inhibition with FK506 ameliorates dendritic spine density deficits in plaque-bearing Alzheimer model mice. Neurobiol Dis 41:650-654.

Rusnak F, Mertz P (2000) Calcineurin: form and function. Physiol Rev 80:1483-1521

Sarasa M, Pesini P (2009) Natural non-trasgenic animal models for research in Alzheimer's disease. Curr Alzheimer Res 6:171-178.

Shimada A, Kuwamura M, Awakura T, Umemura T, Itakura C (1992) An immunohistochemical and ultrastructural study on age-related astrocytic gliosis in the central nervous system of dogs. J Vet Med Sci 54:29-36.

Sompol P, Norris CM (2018) $\mathrm{Ca}^{2+}$, astrocyte activation and calcineurin/ NFAT signaling in age-related neurodegenerative diseases. Front Aging Neurosci 10:199.

Sompol P, Furman JL, Pleiss MM, Kraner SD, Artiushin IA, Batten SR, Quintero JE, Simmerman LA, Beckett TL, Lovell MA, Murphy MP, Gerhardt GA, Norris CM (2017) Calcineurin/NFAT signaling in activated astrocytes drives network hyperexcitability in $\mathrm{A} \beta$-bearing mice. J Neurosci 37:6132-6148.

Song S-K, Sun S-W, Ju W-K, Lin S-J, Cross AH, Neufeld AH (2003) Diffusion tensor imaging detects and differentiates axon and myelin degeneration in mouse optic nerve after retinal ischemia. Neuroimage 20:1714-1722.

Stancu I-C, Vasconcelos B, Terwel D, Dewachter I (2014) Models of $\beta$-amyloid induced tau-pathology: the long and "folded" road to understand the mechanism. Mol Neurodegener 9:51.

Studzinski C, Christie L, Araujo J, Burnham W, Head E, Cotman C, Milgram $\mathrm{N}$ (2006) Visuospatial function in the beagle dog: an early marker of cognitive decline in a model of human aging and dementia. Neurobiol Learn Mem 86:197-204.

Su M-Y, Tapp PD, Vu L, Chen Y-F, Chu Y, Muggenburg B, Chiou J-Y, Chen C, Wang J, Bracco C, Head E (2005) A longitudinal study of brain morphometrics using serial magnetic resonance imaging analysis in a canine model of aging. Prog Neuropsychopharmacol Biol Psychiatry 29:389-397.

Taglialatela G, Hogan D, Zhang W-R, Dineley KT (2009) Intermediate- and long-term recognition memory deficits in $\mathrm{Tg} 2576$ mice are reversed with acute calcineurin inhibition. Behav Brain Res 200:95-99.

Taglialatela G, Rastellini C, Cicalese L (2015) Reduced incidence of dementia in solid organ transplant patients treated with calcineurin inhibitors. J Alzheimers Dis 47:329-333.

Tapp PD, Siwak CT, Estrada J, Head E, Muggenburg BA, Cotman CW, Milgram NW (2003) Size and reversal learning in the beagle dog as a measure of executive function and inhibitory control in aging. Learn Mem 10:64-73

Tapp PD, Siwak CT, Gao FQ, Chiou J-Y, Black SE, Head E, Muggenburg BA, Cotman CW, Milgram NW, Su M-Y (2004) Frontal lobe volume, function, and beta-amyloid pathology in a canine model of aging. J Neurosci 24:8205-8213.

Tapp PD, Head K, Head E, Milgram NW, Muggenburg BA, Su M-Y (2006) Application of an automated voxel-based morphometry technique to assess regional gray and white matter brain atrophy in a canine model of aging. Neuroimage 29:234-244.

Thal DR, Rüb U, Orantes M, Braak H (2002) Phases of A beta-deposition in the human brain and its relevance for the development of AD. Neurology 58:1791-1800.

Tievsky AL, Ptak T, Farkas J (1999) Investigation of apparent diffusion coefficient and diffusion tensor anisotropy in acute and chronic multiple sclerosis lesions. Am J Neuroradiol 20:1491-1499.

Tournier J-D, Calamante F, Connelly A (2012) MRtrix: diffusion tractography in crossing fiber regions. Int J Imaging Syst Technol 22:53-66.

Tustison NJ, Avants BB, Cook PA, Zheng Y, Egan A, Yushkevich PA, Gee JC (2010) N4ITK: improved N3 bias correction. IEEE Trans Med Imaging 29:1310-1320.

Venkatesh A, Stark SM, Stark CEL, Bennett IJ (2020) Age- and memoryrelated differences in hippocampal gray matter integrity are better captured by NODDI compared to single-tensor diffusion imaging. Neurobiol Aging 96:12-21.

Veraart J, Fieremans E, Novikov DS (2016) Diffusion MRI noise mapping using random matrix theory: diffusion MRI noise mapping. Magn Reson Med 76:1582-1593.

Verbitsky M, Yonan AL, Malleret G, Kandel ER, Gilliam TC, Pavlidis P (2004) Altered hippocampal transcript profile accompanies an agerelated spatial memory deficit in mice. Learn Mem 11:253-260.

Vernooij MW, de Groot M, van der Lugt A, Ikram MA, Krestin GP, Hofman A, Niessen WJ, Breteler MMB (2008) White matter atrophy and lesion formation explain the loss of structural integrity of white matter in aging. Neuroimage 43:470-477.

Wang N, Zhang J, Cofer G, Qi Y, Anderson RJ, White LE, Allan Johnson G (2019) Neurite orientation dispersion and density imaging of mouse brain microstructure. Brain Struct Funct 224:1797-1813.

Wieshmann UC, Clark CA, Symms MR, Franconi F, Barker GJ, Shorvon SD (1999) Reduced anisotropy of water diffusion in structural cerebral abnormalities demonstrated with diffusion tensor imaging. Magn Reson Imaging 17:1269-1274.

Wu H-Y, Hudry E, Hashimoto T, Kuchibhotla K, Rozkalne A, Fan Z, SpiresJones T, Xie H, Arbel-Ornath M, Grosskreutz CL, Bacskai BJ, Hyman BT (2010) Amyloid $\beta$ induces the morphological neurodegenerative triad of spine loss, dendritic simplification, and neuritic dystrophies through calcineurin activation. J Neurosci 30:2636-2649.

Yi SY, Barnett BR, Torres-Velázquez M, Zhang Y, Hurley SA, Rowley PA, Hernando D, Yu J-PJ (2019) Detecting microglial density with quantitative multi-compartment diffusion MRI. Front Neurosci 13:81.

Zhang H, Schneider T, Wheeler-Kingshott CA, Alexander DC (2012) NODDI: practical in vivo neurite orientation dispersion and density imaging of the human brain. Neuroimage 61:1000-1016. 